\title{
RELAÇÕES DE SABER-PODER EM UMA ESCOLA DE CIDADE PEQUENA E DO INTERIOR: PROBLEMATIZANDO CONSTRUÇÕES ACERCA DAS HOMOSSEXUALIDADES
}

\author{
KNOWLEDGE-POWER RELATIONS IN A SMALL-TOWN AND \\ COUNTRYSIDE SCHOOL: PROBLEMATIZING CONSTRUCTIONS \\ ABOUT HOMOSEXUALITIES
}

José Rodolfo Lopes da Silva ${ }^{1}$

\begin{abstract}
RESUMO
Quais saberes, sobre as homossexualidades, vêm sendo (re)construídos em contextos de cidades pequenas e do interior? Busco problematizar, a partir das observações e conversas realizadas em uma escola de cidade pequena e do interior, como sujeitos e suas relações vêm sendo (re)construídos, posicionados e administrados no que toca as relações de gênero e sexualidade. Trato tais categorias como resultados de negociações, construções sócio-histórico-culturais e de relações de saber-poder sendo portanto necessário ter atenção aquilo que aprendemos a ver da forma mais "natural possível" como "brincadeiras", "piadas", as divisões de tarefas e atividades. Investir em debates voltados para a diversidade mostra que há olhares voltados para a construção de espaços seguros, do coletivo e de seus indivíduos. A abordagem teórico-metodológica foi construída em diálogo com a perspectiva pósestruturalista, os estudos de gênero e sexualidade e contribuições de Michel Foucault.
\end{abstract}

Palavras-chaves: Saber-poder; Homossexualidades; Cidade pequena; Educar.

\begin{abstract}
How has the knowledge about homosexuality been (re)constructed in the context of small towns and the countryside? Based on the observations and conversations carried out in a small-town and countryside school, I seek to problematize how subjects and their relationships have been (re)constructed, positioned, and managed concerning gender and sexuality relationships. I treat these categories as the results of negotiations, socio-historical-cultural constructions, and relations of knowledge-power. Therefore it is necessary to pay attention to what we learn to see, in the most "natural" way, such as "jokes," the division of tasks and activities. Investing in debates focused on diversity shows concerns focused on constructing safe spaces for the collective and its individuals. The theoreticalmethodological approach was built in dialogue with the post-structuralist perspective, the studies of gender and sexuality, and contributions by Michel Foucault.
\end{abstract}

Keywords: Knowledge-power; Homossexualities; Small town; Education.

\footnotetext{
${ }^{1}$ Mestre em Educação e Especialista em Relações de Gênero e Sexualidades pela Universidade Federal de Juiz de Fora - UFJF. e-mail: jrodolfolopes@ hotmail.com
} 


\section{Revista \\ Debates Insubmissos}

\section{INTRODUÇÃO}

O presente artigo surge como desdobramento de uma pesquisa de mestrado realizada no decorrer do primeiro semestre de 2018 em uma escola de uma cidade pequena/do interior do estado do Rio de Janeiro. Durante aproximadamente quatro meses conversas e observações acerca do cotidiano escolar, de alunos/as e funcionários/as, foram realizadas. A partir desses momentos, realizados em diferentes contextos e espaços como, salas de aula, corredores, refeitório, pátio, quadra, formação de filas e intervalo tive como objetivo problematizar como vinham se (re)construindo as masculinidades nos jogos das relações de saber-poder nesse contexto. Pude perceber continuidades, mecanismos disciplinares e também reconfigurações nessas relações - em meio a uma rotina em que sujeitos se (re)constroem, assim como amizades, saberes, hierarquias e afetos (AUTORIA). Assim, trago dois momentos para problematizarmos como saberes a respeito de sexualidades e expressões de gênero dissidentes se manifestam, vêm sendo (re)construídos, como são vistas/administradas por alguns/mas no contexto. Quais olhares, sujeitos, relações e subjetividades vêm sendo estabelecidos?

Reconheço que uma das dificuldades encontradas no decorrer da pesquisa, mas também potência para o debate, foi a carência de bibliografia que versasse sobre a temática de gênero e sexualidade nessas áreas. A perspectiva teórico-metodológica foi sendo construída em diálogo com a perspectiva pós-estruturalista, os estudos de gênero e sexualidade e contribuições de Michel Foucault que versam sobre as relações de saber-poder, disciplina, resistência e amizade. Caminhos tomados a partir de debates, leituras, problematizações, trocas, caires de muros para a (re)construção de outros olhares e também de escutas. Para se construir uma pesquisa acerca das masculinidades considero importante esse processo para que possamos problematizar as questões a partir de outras verdades, outros olhares ao nos debruçarmos sobre as ações cotidianas, os processos que vem nos (re)constituindo enquanto sujeitos. Enxergo as "brincadeiras cotidianas”, os comentários, a organização das rotinas, a delegação de tarefas como parte do processo de (re)construção de meninos, homens, meninas, mulheres e do saber/fronteira que aprendemos e nos posicionam em relações. Penso assim ser potente e necessário o fomento à discussão sobre os processos de (re)construção em ambientes interioranos/rurais. Torna-se relevante destacar o caráter de multiplicidade e contingência 
desses espaços e não tratá-los como universais e imutáveis. Assim como defendo a diversidade das identidades de gênero, sexualidades, seu caráter poroso e transformador também penso nas cidades de contexto interiorano/rurais como complexas e contraditórias, apresentando suas especificidades, mas também com possíveis aproximações e imaginários construídos. Dessa maneira, dizer dessa pesquisa significa problematizar esses espaços - cidade, escola e aquilo que os/as (re)constrói - a partir de um olhar localizado e particular. Também busco, ao contribuir para a construção de uma bibliografia voltada para esses contextos, impulsionar a realização de outras pesquisas.

As observações e conversas foram realizada com alunos/as dos $6^{\circ}$ ao $9^{\circ}$ ano que estudavam no turno da manhã. $\mathrm{O}$ foco das observações convergiu para como os meninos vêm se (re)construindo enquanto sujeitos, assim como seus saberes sobre o que significa ser homem, suas concepções acerca das masculinidades. Isso não exclui as meninas do processo uma vez que a construção dos gêneros se dá em relação e a partir da imagem que é construída do "outro" (SCOTT, 1995). Como abordagem metodológica busquei inspiração na etnografia. Permiti construir a metodologia em meio ao que o campo mostrava. Não houve uma forma fechada de criar as abordagens e estratégias utilizadas em campo. Permitir que o campo nos mostre os caminhos diz de um olhar atento e constante questionamento para as ações cotidianas, aquilo que aprendemos a ver como "natural", assim como uma circulação/inserção que não seja imposta. Uma preocupação - e atenção - levada para campo era não ocupar espaços e/ou interpelar sujeitos que não se sentissem à vontade.

Segundo Anthony Giddens (2005) a etnografia busca desvendar o comportamento social através da observação participante ou entrevistas. O que busco não é descobrir a "Verdade" sobre esses sujeitos, mas analisar como eles/as vêm se (re)construindo, seus saberes e o que isso engendra em suas relações. Giddens (2005) defende que esse tipo de pesquisa possibilita, quando bem sucedida, uma profusão de informações e maior flexibilidade para o pesquisador que "consegue se adaptar a circunstâncias novas ou inesperadas e seguir de perto qualquer orientação que possa surgir." (Ibidem, p. 515). O autor também destaca possíveis limitações, como por exemplo, grande ou nenhuma identificação com o grupo a ser estudado, 
possibilitando que a pesquisa não se desenvolva ou que um grande envolvimento leve a perda da perspectiva de observador.

Santos (2005) nos convida a pensar que o método e os resultados não se situam em um mundo preexistente. Eles não se encontram à espera de uma melhor aplicação para que seja possível sua emergência. Ou seja, não há um método que esteja separado da teoria, e o próprio método às vezes se constrói no decorrer da pesquisa. Ele propõe o trabalho como um etnógrafoturista, o que significa investir em uma perspectiva que se empenha em reconstruir passos, de uma maneira "que não se coloca como modelo de pesquisa, mas que pretende problematizar a sua própria constituição enquanto metodologia de trabalho, expondo as suas colagens, bem como (...) as suas possibilidades, de forma posicionada, crítica e reflexiva.” (Ibidem, p. 20-21). Isto posto, vim me inspirando para me debruçar acerca das observações realizadas entre os meses de março e julho de 2018. Ações que estiveram em constante diálogo e questionamento, de maneira que não entendesse essas práticas como determinantes, mas sim como contingentes e passíveis de mudança.

\section{DESENQUADRANDO A CIDADE PEQUENA: MULTIPLICIDADES, RUPTURAS E PERMANÊNCIAS}

\footnotetext{
(...) penso que se deve desconfiar das bases sobre as quais se assentam as promessas e as esperanças nas quais nos ensinaram a acreditar. Tudo indica que deveremos sair dessas bases para, de fora, examiná-las e criticá-las. (VEIGA-NETO, 2007, p. 23)
}

No excerto que dá início a essa seção Alfredo Veiga-Neto (2007) destaca como se torna questionável e limitador tentarmos atribuir a realidade a algo. Somos sujeitos, sociedades, lugares e relações de diferentes, dinâmicos e coexistentes configurações sócio-históricoculturais em meio a relações de saber-poder. Assim, penso ser controverso "conceder à visão a possibilidade de revelar como é mesmo a realidade, isto é, a possibilidade de que a visão faça, a um sujeito cognoscente, uma representação correta, talvez às vezes um pouco distorcida, de um suposto mundo real preexistente." (Ibdem, p. 25). Assumo como possibilidade a coexistência de diferentes verdades, suas porosidades, em meio a negociações, assim como a (re)construção das mesmas em meio a esses processos. 


\section{Revista \\ Debates Insubmissos}

Como então classificar cidades pequenas? É possível colocá-las em uma categoria única com as mesmas características? Apostando na problematização ${ }^{2}$ questiono também o que temos entendido e categorizado como cidade do interior. Assim como busco refletir acerca dos processos de desconstrução da "real masculinidade" para a (re)construção das masculinidades - pensando nos diferentes marcadores que nos constituem como raça, sexualidade, geração, nacionalidade, classe, entre outros - o mesmo se dá com a noção desse espaço que é a cidade pequena onde o trabalho de campo foi realizado.

O movimento de problematização acerca das verdades (re)construídas pode se debruçar sobre diferentes debates. Acerca das questões de gênero, sexualidades, raças, ..., e também cidades. Trago informações sobre a localidade como uma forma de situar o/a leitor/a neste espaço, mas não com a intenção de tratar tais características como determinantes para a formação de um sujeito "universal", ou uma cidade pequena "universal”. Busco não estabelecer concepções "reais" do que cidades pequenas e/ou do interior representam. Trabalho com o particular, entendendo que os contextos variam a cada localidade, época, pessoas e diferentes circunstâncias, assim como as verdades dialogam e negociam em meio a isso. Enxergo potência e urgência para ocupar espaços, estabelecer debates, possibilitar que saberes sejam (re)construídos e/ou legitimados - assim como outras relações.

Em meio a isso reconheço as aproximações entre contextos e os cruzamentos de características semelhantes de diferentes cidades interioranas como possibilidade. Portanto busco algumas referências para situar teoricamente alguns entendimentos sobre esses espaços. A edição de 1946 da Revista Brasileira de Geografia traz algumas classificações para esse local. Uma possível classificação para as cidades pequenas brasileiras nesse momento histórico - em começo e ainda em fase de crescimento - "seriam as de populações inferiores a 10000 , ou a 20 000 ou a 30000 habitantes (...).” (SILVA, 1946, p. 299). Para Azevedo (1970, p. 255) as cidades pequenas seriam aquelas que possuem "população urbana superior a 5.000 habitantes, mas inferior a 30.000”. Entretanto essas são classificações datadas. Hoje já podemos perceber um

\footnotetext{
2 Para James Marshall (2008) utilizar a problematização como forma de pesquisa seria dar um passo para trás. Adotar essa metodologia de investigação ainda requer negar verdades absolutas e se afastar de práticas que buscam enquadrar o objeto de estudo de forma totalizante. Trabalhar com condições a serem encontradas e não essências.
} 
movimento que procura discutir a respeito da complexidade em determinar o que seria uma cidade pequena.

Tânia Maria Fresca (2001) destaca a heterogeneidade que envolve a classificação dada a esses espaços. Ela traz essa discussão pensando na multiplicidade de condições e elementos que permitem classificar um espaço enquanto cidade pequena. Uma vez que "nesta classe de cidades vamos encontrar desde aquelas com limite mínimo da complexidade de atividades urbanas até aquelas donde tal complexidade é bastante acentuada, refletindo inclusive, diferenças do ponto de vista populacional.” (Ibidem, p. 28). Ainda buscando inspiração em Fresca (2001), penso ser possível encontrar localidades cujas populações podem oscilar desde 2.000 até 50.000 - e ambas serem consideradas pequenas.

A partir de tais proposições trazemos algumas questões. O que - e por qual motivo - é permitido e o que não é nesses contextos? O que vem sendo ensinado, legitimado, reiterado, (re)produzido? Quais relações, sujeitos, saberes, posições vêm sendo engendradas, administradas, mantidas? Quais são os processos pedagógicos estabelecidos nesses espaços através das mais diversas instâncias - família, escola, mídia, religião, internet, festividades - e as relações estabelecidas consigo mesmo? As respostas para essas perguntas não são únicas, tampouco finais. O movimento de questionamento, debate e de escuta se mostra uma necessidade constante visto que somos sujeitos em constante (re)construção e diálogo com o social.

A cidade escolhida para a pesquisa tem pouco mais de 8.500 habitantes e está localizada na região serrana do estado do Rio de Janeiro. Em seu território há fazendas do ciclo do café e suas atividades econômicas estão concentradas na área agropecuária, indústria com a presença de uma fábrica têxtil e serviços. O município vizinho mais próximo fica a 16 (dezesseis) $\mathrm{km}$ de distância. Localidade que é maior e apresenta mais opções de escolas, cursos, entre outros serviços e atividades. Mesmo tendo mais opções a cidade não é uma metrópole. Possui atualmente pouco mais de 70.000 habitantes segundo o censo de 2010 do IBGE.

A rede municipal de educação possui onze unidades de ensino, localizadas na cidade em que a pesquisa ocorreu e seus distritos. Desse número oito são escolas municipais e três 
são creches. Nem todos os anos escolares são oferecidos nas escolas, fazendo com que alunos/as de áreas mais distantes precisem se deslocar para a escola onde o trabalho de campo foi realizado. Das oito escolas municipais apenas três dispõem os anos finais do Ensino Fundamental $-6^{\circ}$ ao $9^{\circ}$ ano - , sendo que uma delas não possuía o $8^{\circ}$ e $9^{\circ}$ ano. Dessas três escolas apenas uma está localizada no centro do município - a Abbey College $e^{3}$. As outras duas ficam a 9,5 e 6,4 km de distâncias, cada uma, do centro da cidade. Em função dessas questões a escola selecionada para fazer parte da pesquisa foi a mais central.

Durante o século XIX a região era distrito da cidade vizinha. Nessa época o município passou por um processo de colonização e plantação de café, levando ao seu desenvolvimento econômico. Com o passar dos anos a cidade recebe sua emancipação, tornando-se município independente no ano de 1890. O período colonial deixou algumas fazendas do ciclo do café na região. Além disso, o município possui grande diversidade religiosa. Há a presença de diferentes igrejas como católica e neopetencostais. Centros espíritas e de umbanda também se encontram na cidade. Em uma pequena caminhada pela região central é possível ver diferentes igrejas como Católica, Assembleia de Deus, Batista, Ágape e Shekinah.

Em meio a festas, cerimônias religiosas, compras e outras formas de socialização/interação estamos nos (re)constituindo em meio a negociações com o contexto e na relação consigo mesmo. Assim (re)construímos nossos olhares, nossas verdades. Comumente pela ótica da heteronormatividade. Para Richard Miskolci (2012), a heteronormatividade seria o modelo de vida sexual legitimado atualmente em nossa sociedade. Somos criados para ser heterossexuais. Ainda que não nos relacionemos amorosamente com pessoas do sexo oposto somos ensinados a adotar condutas de acordo com a "nossa essência" comumente construída a partir de saberes e relações que vem nos construindo e posicionando na sociedade. Guacira Lopes Louro (2009) também contribui ao problematizar a heteronormatividade como uma norma que estabelece as condutas normais - e anormais, pensando relacionalmente. A conduta normal e universal - portanto "trabalhada" para ser vista

\footnotetext{
${ }^{3}$ Os nomes utilizados, dos sujeitos e da escola, são fictícios como forma de preservar a identidade das pessoas. As falas serão em itálico.
} 
como o natural - está muitas vezes pautada no androcentrismo, eurocentrismo, sujeito de classe social-financeira elevada e religião cristã. Dessa forma, busca-se uma coerência entre sexo, gênero e sexualidade.

Entretanto essas (re)produções não dizem de uma origem, de um sujeito transcendental, mas de condições de emergência, posições que podem ser ocupadas por diferentes indivíduos. Em meio ao discursivo e o não discursivo pessoas, relações, instituições vão sendo moldadas, (re)construídas a partir de determinados saberes. O sujeito do enunciado seria assim:

[...] uma função determinada, mas não forçosamente a mesma de um enunciado a outro; na medida em que é uma função vazia, podendo ser exercida por indivíduos, até certo ponto, indiferentes, quando chegam a formular o enunciado; e na medida em que um único e mesmo indivíduo pode ocupar, alternadamente, em uma série de enunciados, diferentes posições e assumir o papel de diferentes sujeitos. (FOUCAULT, 2008, p. 107)

Problematizo acerca das possibilidades de engendramento corporais e subjetividades em contextos interioranos. Quais masculinidades são produzidas em uma cidade onde os espaços são mais reduzidos e os debates e festividades acabam educando por uma ótica/para uma vida heteronormativa? Buscando me afastar de proposições essencialistas acredito que um fator a ser considerado é que cidades com tais características comumente acabam fazendo com que seus/suas moradores/as circulem por espaços mais concentrados e se conheçam. Tais localidades se mostram como espaços favoráveis para perceber a força discursiva e disciplinar que instituições como igrejas, famílias e escolas mantêm (FERRARI; BARBOSA, 2014).

Em um artigo, que tem como foco as homossexualidades masculinas de uma cidade pequena, Anderson Ferrari e José Barbosa (2014) defendem que é comum perceber um desencontro entre prática e discurso. Era comum não haver debates sobre a questão, ainda que houvesse conhecimento de relações entre homens. Isso dificultava o entendimento sobre os sujeitos que não se encontravam em conformidade com a heterossexualidade. Com isso, por mais que as práticas sexuais e/ou amorosas, antigamente vistas como "proibidas", fossem realizadas ainda havia ausência de posicionamentos políticos voltados para ressignificação de saberes e a diminuição de preconceitos e violências. A produção e manutenção de um discurso heteronormativo como o "natural", aquilo que se encontra na dimensão pública era (re)construído. 


\section{Revista \\ Debates Insubmissos}

Podemos fazer a mesma relação com a questão de gênero. A não discussão sobre tais temas pode produzir um estranhamento cada vez maior de sujeitos que não coadunam com uma ideia binária e/ou heteronormativa. Uma suposta "coerência" em que normas são definidas para homens e mulheres. Isso pode levar a uma condição de abjeção e, por conseguinte a (re)produção de violências físicas e simbólicas - a ponto de serem vistas não como violências, mas brincadeiras, coisas que sempre aconteceram. Assim, o uso de "piadas", "brincadeiras inocentes" reforçam um imaginário, criam um simbólico que autoriza violências, colocam sujeitos em um processo de desumanização.

Saberes são resultados de negociações, processos reiterativos, históricos e agem sobre a (re)constituição dos sujeitos, os posicionam em suas relações e também nas marcas causadas em nossa cultura. Ainda que a Organização Mundial de Saúde (OMS) tenha retirado a homossexualidade da lista internacional de doenças no ano de 1990, muitas pessoas ainda enxergam os homossexuais como anormais, a partir de um viés patológico. Não os reconhecem como seres humanos. No ano de 2019 um grupo de fiscais foi à Bienal do Livro do Rio de Janeiro $^{4}$ para recolher livros que tivessem temática relacionada à homossexualidade. A mando do prefeito da cidade, um evangélico conservador, a ação diz de uma censura e um investimento pedagógico que busca ensinar acerca da/construir uma imagem do homossexual. Ao determinar que o conteúdo é impróprio para menores busca-se educar não para a diversidade e possibilidade de olhar para si como sujeito particular, mas para a limitação e cerceamento dos corpos, das sexualidade, das identidades de gênero. Para fazê-los/as pensar que o correto, o "natural" é ser "homem e mulher de verdade" - sujeitos cisgêneros e heterossexuais. Portanto, aquilo que se mostra em descompasso com o que é ensinado como o "natural" deve ser tirado da visão, do alcance. Necessita ser combatido, censurado, violentado.

${ }^{4}$ Disponível em: https://brasil.elpais.com/brasil/2019/09/06/politica/1567794692_253126.html. (Acesso em: $18 / 06 / 2020)$ 


\section{Revista \\ Debates Insubmissos}

O efeito dessa produção histórica de saberes se torna também sintomático quando é anunciado que o Brasil é o país que mais mata LGBTTTI $+\mathrm{s}^{5}$ no mundo. Segundo pesquisa realizada pelo Grupo Gay da Bahia somente no ano de 2017 foram 445 mortes de pessoas LGBTTTI+s. O número representa um aumento de 30\% em relação a 2016. Quais ações vêm sendo pensadas e efetivadas para ressignificação desses saberes por parte de alguns/mas? Podemos pensar que isso se daria através também da ampliação de outras vozes que aqui nomeio como vozes LGBTTTI+s, as vozes negras, de mulheres, entre outras chamadas minorias? Defendo que a ressignificação dos saberes perpassa também pela escuta, pelo processo de dar um passo para trás, problematizar, para assim construirmos algo novo.

Como pensarmos em novas possibilidades quando os saberes que circulam, se misturam e constróem relações que ainda mantém suposições pautadas na heteronormatividade como o "natural"? Quais investimentos e ações, em que outras sexualidades/identidades de gênero são abordadas, trazidas para discussão cotidiana? Após o término das observações, houve o convite para compor uma mesa de debate em que servidores/as municipais da Secretaria de Educação foram convidados/as a participar. O objetivo do evento era propiciar uma discussão sobre questões de gênero e sexualidade. Éramos quatro convidados/as e cada um/a teve 15 minutos de fala.

Após o término das falas houve um momento para as pessoas realizarem perguntas e/ou fazerem colocações. Um dos participantes pontuou que discordava de algumas questões, pois ele, que era professor da disciplina de Educação Física, acreditava que há diferenças biológicas entre meninos e meninas. Na sua visão meninos são naturalmente mais fortes, fazendo com que isso dificulte atividades mistas - o que levava a "natural" divisão em que meninos jogavam futebol e meninas queimada. Em meio às nossas considerações o professor se mostrava resistente e insistia em pressuposições biológicas e essencialistas que localizam sujeitos de forma binária, a partir de seus órgãos genitais.

\footnotetext{
${ }^{5}$ LGBTTTI é a sigla de Lésbicas, Gays, Bissexuais, Travestis, Transgêneros, Transexuais e Intersexos. A mesma vem passando por variações desde a sua criação. O sinal de mais é uma forma de incluir outras identidades não mencionadas.
} 


\section{Revista \\ Debates Insubmissos}

Em outro momento, durante as observações da pesquisa, foi realizada a feira de livros da cidade. Em meio a programação havia a exibição do documentário bicha preta $\operatorname{doc}^{6}$. Após a exibição do documentário, que aborda e traz para discussão diferentes vivências de pessoas negras que não se identificam como heterossexuais ou cisgêneras, seria realizado um debate com um dos participantes do projeto. Entretanto, devido a um contratempo, ele não conseguiu comparecer à localidade.

Trago ambos os momentos para perceber que há movimentos e olhares para discussões potentes e necessárias. Um trabalho que deve ser feito constantemente - uma vez que, como tantas outras questões, está em constante tensionamento e construção. A iniciativa da Secretaria de Educação e as ações do participante são antagônicas. Mostra a manifestação de diferentes saberes, olhares, tensionamentos, negociações, relações. Dar continuidade aos debates e formação dos sujeitos para a ótica da diversidade diz de um investimento para com o coletivo, com seus indivíduos. Para a construção de espaços seguros em que as pessoas possam se descobrir e desenvolver. Nem todos os meninos terão a aptidão para o futebol - ou meninas para queimada. Em um país em que ser jogador de futebol é constantemente ensinado como sinônimo de masculinidade e sucesso valem reflexões e ações acerca de debates e atividades que busquem diversas representações.

A fala do professor também nos faz refletir sobre como saberes vêm sendo construídos a partir de pressuposições, processos e investimentos que vão comumente sendo engendrados e administrados desde o "anúncio do sexo". O que aconteceria quando um aluno gay, efeminado e/ou franzino tivesse interesse em jogar futebol? Como ele seria recebido? Haveria desestabilizações? Segundo Elisabeth Badinter as masculinidades vêm sendo engendradas a partir da recusa aquilo que aprendemos a enxergar como características femininas, da infância e do homossexual (BADINTER, 1993). Assim, para ser reconhecido como "homem de verdade" é preciso agir e adotar elementos que contrastam com esse imaginário que construímos. Em meio a elementos discursivos e não discursivos as masculinidades - assim

\footnotetext{
${ }^{6}$ Disponível em:

https://www.youtube.com/watch?v=D6RTSy2aS4\&fbclid=IwAR10aslFQDa2TdLPZxFV90ns7W6LN04hZZIW EFN28Ituv13z681TQofapFI (Acesso em: 18/06/2020)
} 
como outros marcadores - vão sendo performados, reiterados e verdades sobre o "ser homem" são produzidas.

Entramos em um processo contínuo em que (re)pensamos nomes, roupas, brinquedos, brincadeiras, acessórios, cortes de cabelo, desenhos que poderão assistir, profissões que poderão seguir, condutas que deverão estabelecer, etc. Saberes que habitualmente ensinam o "ser homem" como o forte, insensível, dominador e "ser mulher" como fraca, sensível e dominada. Como (re)construímos outras possibilidades - pensando nos contextos interioranos e/ou rurais?

Acredito que as conjunturas trazem suas especificidades e dinâmicas. Anderson Ferrari (2005), em sua tese de doutorado, teve como objetivo pesquisar como grupos gays vinham contribuindo, através de comportamentos e pensamentos legitimados, para construir homogeneamente o sujeito homossexual. Entretanto, o que pôde ser percebido é que a visão sobre a categoria homossexual enquanto totalidade vinha passando por enfraquecimentos. Podemos atribuir a busca da universalização como um dos efeitos das ideias iluminista, levando a construção da sociedade moderna. Assim, buscar um exercício de constante reflexão diz de assumir a provisoriedade dos discursos, das relações, dos saberes. Mostram que os contextos em que nos encontramos não dizem de essências, arquétipos definidos e imutáveis. São construções, resultados de ações pedagógicas de caráter sócio-histórico-cultural, portanto passíveis de transformação. Apostar em diversas e humanizadas representações diz de um investimento para como os sujeitos encaram as diferenças, como se constroem enquanto indivíduos.

$\mathrm{Na}$ área de saúde a cidade apresenta 13 estabelecimentos públicos, sendo um hospital central e os outros postos de saúde distribuídos entre o centro e seus distritos. Mesmo quando a cidade não tem a estrutura para algum atendimento é comum fornecerem algum carro que leve pacientes para consultas e exames em cidades vizinhas.

A arquitetura da cidade é mesclada com diferentes temporalidades, desde casas de estilo colonial a outras habitações como prédios e casas com construções mais recentes. Mesmo com um relativo crescimento nos últimos anos as casas ainda prevalecem no cenário 
arquitetônico do município. Os prédios - construídos mais recentemente em sua maior parte raramente ultrapassam três andares. As ruas da cidade ainda são em boa parte preservadas com suas pedras de paralelepípedo, mas em outras partes suas estradas são asfaltadas. Entretanto, alguns trechos estão deteriorados apresentando grandes e numerosos buracos. Ainda há regiões onde as estradas são de terra, fazendo com que em época de chuvas muito fortes os ônibus escolares não consigam buscar os/as alunos/as.

A configuração do município vem se distanciando de uma ideia engessada do que uma cidade pequena representa no imaginário. Apesar de não possuir algumas "opções de cidades cosmopolitas" - como, por exemplo, cinemas, redes de restaurante fast food, shopping centers e teatros com grandes produções - é possível ver a presença da tecnologia, especialmente com mais jovens. Há pessoas em seus celulares, seja nas ruas ou na escola. Podemos pensar que há uma questão paradoxal. Ao mesmo tempo em que a cidade "não tem nada", ela mostra a possibilidade de se conectar com o mundo para além da sua dimensão geográfica. A internet possibilita o alcance a diferentes informações, conteúdos e sujeitos. Possibilita a cidade se abrir para o mundo, assim como o mundo chegar até a cidade. Acesso à/disponibilização de diferentes conteúdos, pessoas, relações, saberes. Processos que também (re)constroem esses sujeitos, esses contextos. Algo improvável há poucos anos atrás.

Mesmo não havendo opções culturais e de entretenimento sendo oferecidas todas as semanas é comum ver os/as jovens ocupando espaços. Alguns/mas deles/as se concentram na praça central, onde conversas são trocadas. Também é possível vê-los/as sentados/as nas escadarias que são parte do acesso à igreja matriz do município. Há meninos que andam de bicicleta pelas ruas durante as tardes e grupos - pequenos ou não - que andam pelas ruas voltando de alguma atividade ou simplesmente de forma descompromissada. Também há grupos de meninos sentados pelas quadras e em mesas de lanchonetes à noite e no fim de semana ou encostados nas entradas das casas. É comum o deslocamento para a cidade vizinha - ou outras ao redor e mais distantes - como forma de buscar festas e outras atividades. Esses grupos também são comumente divididos e organizados por gênero. 


\section{AS PERFORMANCES DA/NA ESCOLA DA MODERNIDADE}

A instituição escolar tem sido objeto de debates em diversos contextos. A sua importância, seus sucessos, caminhos, fracassos e futuro são alguns dos temas que subjugam essas discussões. Para Alfredo Veiga-Neto (2003), entretanto, se torna necessário entender como ela se tornou o que é. Pensar como ela se implica com a sociedade e como podemos compreender as mudanças no social a partir dela. Buscando ordenar e civilizar as pessoas, a escola teve um grande papel na transformação das pessoas "selvagens" em "civilizadas". Contudo, isso não garante a ela a exclusividade de agente transformador da modernidade.

Em Vigiar e Punir, Michel Foucault (1999) mostra que esse modelo disciplinar presente na escola não surge repentinamente. Ele é resultado de processos históricos e saberes que nos organizam em relações de poder. Modelo que busca individualizar os sujeitos ao máximo, tornando-os/as dóceis, úteis com seus corpos disciplinados e homogêneos. Para ser disciplinado/a é preciso aprender a se relacionar não só consigo, mas também com os espaços, instituições, com o tempo, com amigos/as, família, professores/as, autoridades, entre outros.

A modernidade é um momento em que a racionalização dos saberes e a busca por verdades absolutas através da ciência se dá de forma acentuada. Segundo Michael Peters (2000), o modernismo se instaurou como um movimento alicerçado na certeza do avanço epistemológico, um desdobramento da experiência através do método científico. Podemos pensar em uma fragmentação da legitimidade conferida à religião, vista até então como fonte de todas as respostas, e uma compreensão da ciência como produtora de respostas "mais objetivas", portanto irrefutáveis.

Muitos/as alunos/as, de diferentes regiões do município, chegam através de ônibus escolares. Alguns/mas chegam a pé e outros/as são deixados/as de carro. Também é possível perceber a organização de grupos divididos. Meninos e meninas se agrupam - de uma forma geral - separadamente. A organização não se dá apenas pelas companhias formadas. Há elementos, como, por exemplo, cortes de cabelo, vestimentas, acessórios, mochilas, e posturas que dividem e arranjam esses sujeitos. Isso pode ser identificado em alunos/as, professores/as e outros/as funcionários/as. Sinais variados que fazem - em inúmeros momentos - com que 
acionemos saberes que classificam os sujeitos nessas caixinhas - ser homem e ser mulher construídas socialmente. Há saberes sobre o feminino e o masculino construídos que estão em diálogo com a cultura heteronormativa e binária.

A escola da modernidade - mas também a mídia, família, redes sociais, entre outros habitualmente, em meio a elementos discursivos e não discursivos, constrói, administra, agrupa e classifica, da forma mais "natural" possível, a heterossexualidade. Quais debates vêm sendo feitos, quais histórias vêm sendo contadas, quais narrativas vêm sendo (re)produzidas, quais olhares vêm sendo (re)construídos? Esse processo de (re)construção é costumeiramente feito de uma forma que valoriza limitadas - e inalcançáveis - formas de vida. Referência a um sujeito - o homem branco, cisgênero, heterossexual, cristão, monogâmico - como sendo universal, figura desejável e positiva - portanto aquilo que for seu oposto seria inferior, patológico, negativo. Assim hierarquias são criadas e naturalizadas. Duvidar desses processos torna-se urgente para que possamos enxergar as questões racistas, machistas, misóginas, LGBTTTI+fóbicas como construções. Violências físicas e simbólicas que atravessam nossas relações e nos constituem enquanto sujeitos. Logo como algo que pode e deve ser combatido, desconstruído para se criar algo novo - outras formas de ser, de (se) relacionar. Para isso devemos voltar o nosso olhar para as atividades do dia a dia, os gestos, olhares, comentários e "piadas". Devemos desconfiar do que é visto como o "natural" (LOURO, 2003; FERRARI, 2007).

Anderson Ferrari e Wescley Dinali problematizam a construção do sujeito dentro desse modelo educacional (2012). Para eles a instituição escolar age como uma máquina, um instrumento que controla e organiza os corpos. Ela busca não só construir o sujeito disciplinar, mas também a própria Modernidade, garantindo assim a sua manutenção e preservação. Tudo isso buscando maior produtividade desses corpos, processo que não se encerra, é instável, incompleto e está em constante arranjo. Uma vez que o poder disciplinar é produtivo podemos considerar que a disciplina também pode produzir saberes acerca da homossexualidade, agindo sobre os sujeitos em meio a este contexto - independente de sua orientação sexual e/ou identidade de gênero.

Segundo Michel Foucault (1999, p. 143): 


\section{Revista

O poder disciplinar é com efeito um poder que, em vez de se apropriar e de retirar, tem como função maior "adestrar"; ou sem dúvida adestrar para retirar e se apropriar ainda mais e melhor. Ele não amarra as forças para reduzi-las; procura ligá-las para multiplicá-las e utilizá-las num todo. Em vez de dobrar uniformemente e por massa tudo o que lhe está submetido, separa, analisa, diferencia, leva seus processos de decomposição até às singularidades necessárias e suficientes. "Adestra" as multidões confusas, móveis, inúteis de corpos e forças para uma multiplicidade de elementos individuais - pequenas células separadas, autonomias orgânicas, identidades e continuidades genéticas, segmentos combinatórios. A disciplina "fabrica" indivíduos; ela é a técnica específica de um poder que toma os indivíduos ao mesmo tempo como objetos e como instrumentos de seu exercício.

Foucault (1999) chamava a atenção para semelhanças entre a escola da modernidade e a prisão. Meios de confinamento onde se extrai o máximo de utilidade dos corpos ali presentes. Podemos fazer relações com o uso de uniformes, cadeados, grades, horários organizando o dia e atividades, horários das refeições, pessoas vigiando, controlando e direcionando - para que possamos lograr o sucesso que esse projeto da modernidade nos promete. Com suas distinções é possível perceber que em muitos momentos o modelo estrutural da prisão se aproxima fortemente da escola. Estratégias/saberes são estabelecidos, vão nos organizando e instituindo formas de disciplinar. Formas de ser, estar e agir em determinados contextos.

Não atribuo a instituição escolar total responsabilidade, tratá-la como a origem dessas questões. Também não espero que ela seja homogênea com suas práticas e saberes. Assumo que há diferentes contextos e possibilidades que diversificam de acordo com as instâncias culturais, sociais e econômicas. Entretanto, é preciso considerar que mesmo com "a ampla variedade de práticas e saberes escolares, dos diferentes tipos de escola, dos seus distintos perfis e objetivos frente aos estratos sociais ao qual ela se destina, é fácil compreender que todas elas partilham de pressupostos, metas e lógicas comuns." (VEIGA-NETO, 2008, p. 38). Assim é preciso nos perguntar em que escola e cidades interioranas desejamos investir, (re)construir. Escolas e cidades para quem? Como se sentem alunos/as de orientação sexual e/ou identidade de gênero dissidentes nesses contextos? Quais ações e debates vêm sendo pensados e desenvolvidos nesses espaços?

Considero o projeto escolar da modernidade como algo performativo, que vem sendo encenado, reiterado, reconfigurado, administrado e naturalizado. A partir dela, mas não somente, vem sendo estabelecidas noções de sucesso, disciplina, do/a "bom/a aluno/a" e do/a 
"aluno/a ruim". Ela vem possibilitando construir as noções da heteronormatividade e da cisgeneridade como as naturais, as corretas e em um processo de relação outras identidades de gênero e/ou orientações sexuais como patológicas, mundanas, incorretas. Em 2019, uma escola particular de Belém ${ }^{7}$ aplicou uma prova de língua portuguesa que tinha como base um livro que, dentre outras questões, abordava a homossexualidade como uma doença, algo possível de ser evitado. O livro chega a utilizar o termo homossexualismo e propor que motivos possíveis para a sua causa seriam o menino passar muito tempo com mulheres e/ou crescer em um ambiente no qual o pai é fraco ou ausente.

Em meio a ações violentas - física e simbolicamente - podemos também vislumbrar outras condutas. No ano de 2016 o Colégio Pedro II, a partir da portaria n $^{\mathbf{0}}$ 2449/2016 ${ }^{8}$, aboliu a distinção do uniforme escolar fazendo com que não houvesse mais especificação acerca do que são uniformes feminino e masculino. Tal ação nos mostra outros caminhos possíveis, mas não únicos, para nos inspirarmos e pensarmos em como (re)construirmos espaços seguros, que entendem o compromisso da instituição escolar em educar/formar cidadãos/ãs. Também nos permitem vislumbrar que a escola, a sociedade e os espaços estão em constante negociação e tensionamento com os contextos, sujeitos, relações de saber-poder e resistência. É importante ter atenção para quais olhares vimos construindo, para quem, assim como para os desdobramentos dessas ações.

\section{4. “O CARLOS ELE É MEIO ESTRANHINHO (SIC), ELE É DIFERENTE. EU ACHO QUE É PORQUE ELE NÃO SE DECIDIU AINDA.”}

A "fabricação" dos sujeitos não se dá de uma única maneira. Temos aqueles/as que escapam das expectativas que a sociedade imputa como natural. Tomam outros cursos, criam outras narrativas e outras possibilidades. Carlos, aluno do $6^{\circ}$ ano, era um dos meninos que eu

\footnotetext{
${ }^{7}$ Disponível em: https://g1.globo.com/pa/para/noticia/2019/11/19/familia-denuncia-escola-particular-por-passarprova-contendo-perguntas-homofobicas-em-belem.ghtml (Acesso em: 09/06/2020).

${ }^{8}$ Disponível em: http://www.cp2.g12.br/images/comunicacao/2016/Setembro/portaria2449.pdf (Acesso em: 09/06/2020).
} 


\section{Revista \\ Debates Insubmissos}

percebia se distanciar em alguns momentos de uma ideia de masculinidade (re)produzida neste contexto. Um dia, no começo das observações, ele estava brincando de adoleta $^{9}$ com uma monitora. Seu jeito de andar, falar, sua voz e seus trejeitos são interpretados por algumas pessoas - funcionários/as e colegas - como "femininas".

Patrícia, uma das inspetoras, expressou suas impressões sobre o aluno durante uma conversa. "O Carlos ele é meio estranhinho (sic), ele é diferente. Eu acho que é porque ele não se decidiu ainda.". Perguntei o que ela achava que ele não tinha se decidido. "Ah, se gosta de homem ou de mulher. Ele é muito novo.". Questiono então se não há a possibilidade dele se interessar pelos dois. "Acho que não, você olha pra ele e dá pra ver que tem alguma coisa diferente.".

Neste momento não foi preciso classificar Carlos como gay. Há um saber constituído em Patrícia que o posiciona nessa relação. Saber marcado pela cultura heteronormativa e binária. Dessa forma, o aluno é enquadrado como o "estranhinho", o "diferente", algo que não pode ser nomeado. Discursivamente ela o posicionou, o classificou e ficou marcado o que ela quis dizer. Havia na fala da monitora a busca por uma coerência da parte de Carlos. Uma vez que ele apresentava traços "femininos" já se esperava que ele estivesse em dúvida sobre sua sexualidade. Pessoas que não se conformam aos padrões de gênero comumente têm suas condições enquanto sujeitos questionadas. "Em sendo a 'identidade' assegurada por conceitos estabilizadores de sexo, gênero e sexualidade, a própria noção de "pessoa" se veria questionada pela emergência cultural daqueles seres cujo gênero é 'incoerente' ou 'descontínuo' (...)" (BUTLER, 2003, p. 38).

A fala da monitora ainda faz com que duas questões me atravessem. Primeiramente como há habitualmente processos de invisibilização/negação da bissexualidade enquanto válida e uma possibilidade de explorar os desejos. Também penso como os desejos e sujeitos que não estão em consonância com a heterossexualidade têm sua legitimidade questionada. São tratados como indecisão, uma fase, um momento de experimentação enquanto a heterossexualidade é

\footnotetext{
${ }^{9}$ Brincadeira onde os participantes batem a mão do outro participante enquanto cantam a música que dá nome a brincadeira.
} 


\section{Revista \\ Debates Insubmissos}

tomada por muitos/as como natural, esperada e desejada. Ela não precisa ser questionada. "Estranhinho" não é sinônimo da heterossexualidade. Ela é produzida como promessa de certezas, da felicidade, do amor, da moral, do afastamento do pecado e do impuro -há todo um projeto de vida e sociedade vinculado a essa forma de viver a sexualidade. "A norma não precisa dizer de si, ela é a identidade suposta, presumida; e isso a torna, de algum modo, praticamente invisível" (LOURO, 2000a, p. 68).

As formas como enxergamos as sexualidades e os gêneros são resultados de negociações e construções; nada é automático ou possui uma essência. São saberes que vamos adquirindo a partir de discursos médicos, religiosos, familiares e/ou escolares, entre outros. Discursos que também vão nos educando e usualmente não são problematizados. Levando a crença e perpetuação de verdades absolutas, cristalizadas. Conduzindo a legitimação de determinados sujeitos em detrimento de outros. Deborah Britzman tensiona a suposta naturalidade que aprendemos a atribuir a heterossexualidade - assim como qualquer outra - quando afirma que:

Nenhuma identidade sexual — mesmo a mais normativa — é automática, autêntica, facilmente assumida; nenhuma identidade sexual existe sem negociação ou construção. Não existe, de um lado, uma identidade heterossexual lá fora, pronta, acabada, esperando para ser assumida e, de outro, uma identidade homossexual instável, que deve se virar sozinha. Em vez disso, toda identidade sexual é um constructo instável, mutável e volátil, uma relação social contraditória e não finalizada (1996, p. 74 - grifos da autora).

Muitas das interações entre os meninos envolviam xingamentos e palavrões. Durante um horário vago, um deles gritava "Filho da puta!" repetidas vezes enquanto jogava com seu celular. Os gritos eram uma forma de expressar seu descontentamento com os erros que cometia no jogo. Um chamou a atenção do colega por considerar seu aperto de mão muito fraco. "Aperta igual homem ô viado." ele disse. Outro, ao ver um colega voltando do banheiro e subindo a rampa, bravejou de forma bem enfática: “ÊE Pedro Rodrigues, seu merda. Seu viado.”. Os dois trocaram olhares e risadas, mostrando que aquela era uma forma "natural" de "brincarem" um com o outro. Isso ficou ainda mais evidente nos momentos em que o/as inspetores/as chamaram suas atenções e eles disseram que aquilo não era nada sério. Um dos alunos chegou a dizer "Ué, mas a gente só tá brincando. Não pode nem mais brincar agora?". Tais interações nos permitem problematizar como saberes vêm se construindo, se manifestando e se costurando nessa teia de relações. Quais processos vêm sendo reiterados, performados, a ponto que nós 
Revista

Debates Insubmissos

enquanto sociedade e a escola enquanto instituição passemos a naturalizar certas ações e ter olhares urgentes para outros? O que deixamos de perceber com os olhares que vimos (re)constiuindo?

\begin{abstract}
Tal "naturalidade" tão fortemente construída talvez nos impeça de notar que, no interior das atuais escolas, onde convivem meninos e meninas, rapazes e moças, eles e elas se movimentem, circulem e se agrupem de formas distintas. Observamos, então, que eles parecem "precisar" de mais espaço do que elas, parecem preferir "naturalmente" as atividades ao ar livre. Registramos a tendência nos meninos de "invadir" os espaços das meninas, de interromper suas brincadeiras. E, usualmente, consideramos tudo isso de algum modo inscrito na "ordem das coisas". (...) Mas as divisões de raça, classe, etnia, sexualidade e gênero estão, sem dúvida, implicadas nessas construções e é somente na história dessas divisões que podemos encontrar uma explicação para a "lógica" que as rege. (LOURO, 2003, p. 60-61).
\end{abstract}

Connell (1995) destaca a estrutura complexa do gênero e chama a atenção de dois aspectos para pensarmos sobre as (re)construções das masculinidades. Primeiramente as masculinidades são produzidas de diferentes maneiras no mesmo contexto social, então por mais que haja uma forma hegemônica de masculinidade outras possibilidades se encontram agrupadas ao seu redor. A pesquisadora ainda diz que "qualquer forma particular de masculinidade é, ela própria, internamente complexa e até mesmo contraditória.” (Ibdem, p. 189), uma vez que é possível encontrar atributos "femininos" em homens e vice-versa.

A hegemonia pode ser pensada de forma líquida, fluída. Não é algo que se possui, mas sim algo que se exerce. Algo que está em constante processo de disputa e mudança, em diferentes contextos. Zygmunt Bauman (1999) defende que nos tornamos seres desassossegados/as, em movimentação contínua. Vivemos em uma sociedade marcada pelo aumento no trânsito de saberes e sujeitos pelo corpo social. Movimento que é constante, seja ele no aspecto físico e/ou simbólico. É importante ter cautela para não pensar as relações entre homens e mulheres de forma maniqueísta. O machismo, sexismo, a LGTTTI+fobia e a misoginia são questões que atravessam as relações sociais, mas há disputas em campo que tornam as relações mais complexas.

Para Anderson Ferrari o enquadramento é uma forte característica de nossa sociedade. Segundo ele "estamos "acostumados" a enquadrar todos/as, definindo-lhes lugares, identidades, ações, o que deve o que não deve ser feito, o "certo" e o "errado"” (Ibidem, 2009, p. 121). Podemos pensar que isso se dá desde o momento em que "é revelado o nosso sexo". A partir 
desse anúncio se dá início a diferentes investimentos para que um "menino" ou uma "menina" sejam construídos/as, comumente realizados dentro de uma lógica heteronormativa.

Ferrari se apoia em Foucault fazendo relação do enquadramento com a hipótese repressiva que é defendida por Foucault (1988). Seria uma forma de poder que não pode "prescindir da vida e do corpo. O corpo se torna objeto e objetivo do poder, como algo que deve ser investido, corrigido, formado e disciplinado.” (FERRARI, 2009, p. 121). Em um longo processo vamos sendo enquadrados por diferentes instituições como família, escola, religião, entre outras. "Enquadrar quer dizer por no quadro, dar contorno, desenvolver tipos de práticas que diminuem a fluidez para ser diferente do que está estabelecido.” (Ibdem, p. 122).

Não há um processo unilateral ou neutralidade, todos/as estão dentro do mesmo jogo, com seus conhecimentos sobre gênero, sexualidade e identidade. A identidade é marcada pela diferença, que por sua vez é sustentada pela exclusão: se você é homem, você não pode ser mulher, e vice-versa (WOODWARD, 2009). Gênero e sexualidade vão se estabelecendo como organizadores sociais, culturais, de nossas relações e vamos sendo enquadrados/enquadrando nessas relações com o(s)/a(s) outro(s)/a(s). Acionando diferentes saberes, o/a outro/a busca classificar e com o passar do tempo entramos nesse jogo, pouco a pouco entramos em um processo de negociação e vamos nos organizando para ser aquilo que dizem (ou o contrário), mas sempre vamos dialogando com o social e nos constituindo.

Há muitas pessoas que acreditam que a heterossexualidade, assim como o "ser homem" e o "ser mulher" são intrínsecos a nós. Algo natural, uma substância que se encontra em nossos corpos. A nossa essência. Pensamentos que vão marcando nossas relações, determinando aquilo que deve e o que não deve ser feito. Enquadramentos que frequentemente não permitem um homem chorar porque é "coisa de mulherzinha", reprimem o rapaz que não “pega a mulher” porque se ele não fizer nada sua sexualidade já é colocada sobre suspeita. Caçoam daquele que não joga futebol supondo que essa pessoa "apresenta algo errado". Acontecimentos que além de reproduzirem violências, constroem os nossos corpos, os nossos olhares, os nossos desejos, as nossas subjetividades. 
Concatenar as identidades é sempre um processo de negociação e enquadramento. Também diz respeito à construção das diferenças. Marcamos assim o que é o "certo" e o “errado", o “aceitável” e o "inaceitável” (FERRARI, 2009). Sujeitos vão sendo posicionados no corpo social e às vezes tendo suas ações questionadas. Um exemplo são os homens com performances dissidentes, que se afastam da masculinidade cultuada, ensinada socialmente. A partir do momento em que eles não condizem com a masculinidade hegemônica eles passam por questionamentos e um novo enquadramento, o da homossexualidade. Embora seja recorrente a relação entre o enquadramento com a homossexualidade e a expulsão do gênero masculino, isso não afasta essas pessoas do gênero. Eles continuam sendo homens.

Dessa maneira, os gêneros assim como as sexualidades são construídos a partir de rituais, símbolos, linguagens, etc. (LOURO, 2000b). Isso faz com que nos separemos dessa proposição "natural". Provoca nossas lentes de forma que passamos a perceber as hierarquias naturalizadas, comumente pensadas como imutáveis, entre os sujeitos e suas relações. Faz com que nossos olhares se abram para a diversidade. Permite que nós abarquemos as pluralidades que estão neste mundo. Enxergando além de um campo que nos fazem acreditar que o universal, o correto, o desejado/desejável é ser binário e heterossexual. Entretanto essas caixas podem ser limitadoras/limitadas. Caixas que vão nos constituindo, formando nosso olhar, nossos saberes e marcando as nossas relações.

\section{5. "AH, ELE SEMPRE VAI EMBORA COMIGO. A GENTE MORA PERTO E SEMPRE VAI SOZINHO E ELE NUNCA TENTOU NADA."}

As observações e conversas na Abbey College me fizeram refletir que não podemos tratar os processos disciplinares de forma unilateral - onde apenas funcionários/as exercem esse poder sobre alunos/as. Em diversos momentos os/as estudantes também tinham investimentos sobre seus/suas colegas. Eles/as também incorporam desde cedo o papel do/a disciplinador/a nessa sociedade de controle. Controle que vai "das disciplinas fechadas, espécie de "quarentena" social, até o mecanismo indefinidamente generalizável do "panoptismo". (FOUCAULT, 1999, p. 239). A disciplina proporciona assim que as relações de poder se 


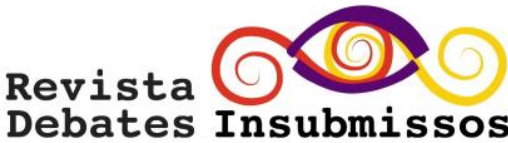

distribuam, fazendo com que todos/as possam exercer a posição do/a disciplinador/a. Cria-se uma função "natural", olhares e ações são educados, incorporados: a partir dessas lentes educamos a nós mesmos e aprendemos como agir sobre o "outro" de forma que a disciplina se espalha pelo corpo social, trazendo dinamicidade e fluidez para o panóptico.

Uma das formas era através da utilização da expressão "viado" (sic) como xingamento para a marcação e enquadramento de algum amigo. Xingar um amigo de "viado" (sic) não estava necessariamente ligado ao entendimento sobre a sua sexualidade. Desafiar e colocar o gênero como uma questão através de perguntas como "Você não é homem?" também eram práticas comuns. Categorizar alguém dessa maneira era feito a partir de saberes sobre sexualidade e masculinidade. Algo que reforçava posições, educava sobre "ser homem", sobre "ser homossexual" e agia sobre os corpos. Uma tentativa de trazer essas pessoas que atravessavam a fronteira para seus devidos lugares. Mostrar que o "lado de lá" não é o correto. Que esse lado é do outro, das meninas, portanto deve-se voltar para o dos meninos. Iniciavamse ações pedagógica que se espalhavam sobre o contexto e seus sujeitos.

O $9^{\circ}$ ano da escola - só havia uma turma - era sempre elogiado por todos/as. Professores/as teciam bons comentários sobre os/as alunos/as. A direção e orientação raramente recebiam reclamações. Havíamos decidido que seria importante acompanhar as aulas de todas as turmas no decorrer do primeiro mês. Habituar-se e perceber como seus sujeitos se relacionavam. Dessa forma, perguntei a professora Roberta na chegada à escola se poderia assistir uma das aulas da turma. "Claro que pode, hoje eu estou lá nos dois últimos horários.", ela disse (Diário de campo, 11 de abril de 2018). Combinamos então que naquele dia estaria lá para acompanhá-la.

Assim que o sinal anunciou o fim do recreio me direcionei para a porta da sala - que ficava no $2^{\circ}$ piso - e aguardei a professora na porta. Ela logo chegou, me apresentou para a turma e disse que naquele dia eu ficaria com eles/as durante a aula. Os/as alunos/as me cumprimentaram e voltaram logo para suas conversas. Sentei-me em uma carteira logo na frente e aguardei o início da aula. A professora explicou que precisava aplicar a prova para uma aluna que ainda não a tinha realizado. Ela também aproveitaria o momento para corrigir o restante das provas. Assim, ela pediu a colaboração de todos/as para que a colega pudesse fazer a prova. 


\section{Revista \\ Debates Insubmissos}

Os/as alunos/as acabaram ficando mais livres e se dividiram em três grupos nesse momento. Três meninas e um menino se reuniram mais ao fundo da sala para conversar. Outro grupo maior, com sete alunos, fez um círculo e decidiu jogar adedanha ${ }^{10}$. O terceiro grupo era composto de quatro meninas que aproximaram suas carteiras e deram início a uma conversa. $\mathrm{O}$ tempo assim foi passando. Em alguns momentos a professora precisou chamar a atenção dos/as alunos/as por estarem falando muito alto. Caio - um dos alunos - disse que não queria mais jogar adedanha e perguntou a professora se ela não podia emprestar sua caneta piloto para que ele desenhasse no quadro. Ele comumente estava na companhia de meninas e apresentava trejeitos mais delicados. Tinha uma estatura média, corpo esguio e cabeça raspada.

Assim que ele começou a desenhar percebi que seu traço era firme e fluído. Sua habilidade também foi reconhecida por seus/suas colegas. Seus/suas amigos/as nesta hora já haviam parado de jogar e um grupo se formou ao seu redor. Eles/as o observavam enquanto as linhas tomavam a forma de um castelo. Uma das alunas elogiou o desenho que já ocupava boa parte do quadro. Caio desenhava bem. Estava tão concentrado e imerso em sua atividade que até parecia não haver pessoas a sua volta.

Um menino trocou olhares de cumplicidade com seus/suas outros/as colegas que riam. Ele então deslizou os dedos pelas costas de Caio fazendo com que ele se assustasse. O cóccix foi o primeiro lugar que os dedos encostaram. Uma aluna, se referindo a Caio, logo disse: "Ele é viado (sic), cara.". "Talvez ele corte pros dois lados" disse outra. Outra colega passou levemente as longas unhas nas suas costas como se estivesse as arranhando. Ele se assustou mais uma vez e riu sem graça, com o rosto ruborizado. A aluna então de repente comentou: "Ah, ele sempre vai embora comigo. A gente mora perto e sempre vai sozinho e ele nunca tentou nada.". Caio riu visivelmente constrangido, mas não falou nada. O que cabe a meninos e meninas em uma relação? A amizade é vista por muitos/as como algo improvável, pois se o menino se aproxima ele só pode estar pensando em dar em cima da menina. Como Caio nunca "tentou nada", sua sexualidade e sua masculinidade foram postas em dúvida. Algo a ser

\footnotetext{
${ }^{10}$ Jogo também conhecido como stop, que consiste em utilizar uma folha de papel e estabelecer temas como, por exemplo, nome, cor, lugar, comida, entre outros. Dessa forma os/as participantes devem preencher essas categorias a partir de uma letra sorteada, testando assim conhecimentos gerais e específicos.
} 
questionado, disciplinado e exposto na frente de todos/as. A sala se tornou um tribunal, onde Caio foi julgado, categorizado e enquadrado a partir de diferentes saberes. Saberes educados constantemente através de diversas instâncias. Uma vez que alguém não corresponde a um "padrão hegemônico", "natural", dá se início a fiscalização. Processos pedagógicos que ensinam, através da exposição sobre o gênero e a sexualidade "desviante", sobre a "verdade" que Caio carrega.

O corpo humano entra numa maquinaria de poder que o esquadrinha, o desarticula, e o recompõe. Uma "anatomia política", que é também igualmente uma "mecânica de poder", está nascendo; ela define como se pode ter domínio sobre o corpo dos outros, não simplesmente para que façam o que se quer, mas para que operem como se quer, com as técnicas, segundo a rapidez e eficácia que se determina. A disciplina fabrica assim corpos submissos e exercitados, corpos "dóceis". A disciplina aumenta as forças do corpo (em termos econômicos de utilidade) e diminui essas mesmas forças (em termos políticos de obediência). Em uma palavra: ela dissocia o poder do corpo; faz dele por um lado uma "aptidão", uma "capacidade" que ela procura aumentar; e inverte por outro lado a energia, a potência que poderia resultar disso, e faz dela uma relação de sujeição estrita. (FOUCAULT, 1999, p. 119).

O corpo de Caio parecia estar tão disciplinado que a única reação possível nesse momento foi o não enfrentamento. Ele não reagiu, seu corpo parecia de certa forma atrofiado. Dava risadas encabulado, a boca nem se abria direito. O que acontece com aqueles/as que são expostos/as diariamente a um mecanismo de controle tão intenso? Como sujeitos que passam por esses esquadrinhamentos e enquadramentos - não só o ser "viado" (sic), mas também assimilar isso como algo ruim, aquilo que não deveria ser - acabam se enxergando?

Caio não confirmou em nenhum momento as suspeitas e suposições que seus colegas faziam sobre sua sexualidade. A ação de seus/suas colegas mostra como relacionamos normas de gênero a sexualidade, como buscamos "coerência" entre essas duas categorias. O que faz com que um menino que demonstra interesse, aproximação por coisas ditas como femininas seja classificado como homossexual? Para Niall Richardson (2009) o homem efeminado se torna - variando de contexto para contexto - uma fonte de medo ou de gozação. (Re)produz-se a rejeição daquilo que é entendido como próprio do feminino no masculino, um sentimento não necessariamente de homofobia, mas de efeminofobia.

A efeminofobia também é uma ação misógina, que inferioriza qualquer homem que se aproxime do "feminino", e, por conseguinte a própria construção do "feminino". Termos como 
"mulherzinha" e "bichinha" nos mostram como a linguagem vai sendo produzida, administrada, reiterada ao ponto de enxergarmos características como naturais, de forma hierárquica e como ela constrói sujeitos e relações. Richardson ainda diz que isso não atinge apenas pessoas que se identificam como heterossexuais. Também alcança e constitui parte da cultura homossexual e seus sujeitos. Isso se manifesta, por exemplo, quando homens rejeitam outros homens enquanto parceiros amorosos/sexuais por serem entendidos como muito efeminados. $\mathrm{O}$ homem efeminado desafia a naturalidade do gênero, a heteronormatividade como uma essência. Desconstrói as ideias essencialistas de gênero, dos padrões de masculinidade e feminilidade. Afinal, se muitos acreditam que o "ser homem" é tão garantido por que toda uma preocupação e constante vigilância com seus trejeitos, vestimentas, tom de voz e outros elementos?

\section{CONSIDERAÇÕES FINAIS}

O presente artigo teve como objetivo problematizar as relações de saber-poder, tendo como recorte as (re)construções acerca da homossexualidade e identidades de gênero dissidentes, em cidades pequenas/do interior. Parto do princípio que os elementos discursivos e não discursivos dizem não de uma essência, mas de diferentes processos sócio-históricoculturais sendo portanto anteriores a seus sujeitos e espaços. Em meio a contingência, naturalizações e legitimações sujeitos, relações, espaços e cidades vêm sendo (re)constituídas comumente privilegiando as construções heteronormativas como as "naturais" - portanto não questionáveis, não suscetíveis à exposição, categorização e/ou diminuição de sua orientação sexual e/ou identidade de gênero.

Discursos são possíveis porque outros discursos - médico, legal, midiático, entre outros - vêm nos educando, permitindo as suas emergência e projeção. São elementos das relações de saber-poder levando a (re)produção, reiteração e administração de sujeitos, práticas, cidades, escolas. É preciso atentar-se para aquilo que aprendemos a ver como o "natural", as "brincadeiras sem maldade" e assumir que a linguagem produz verdades que podem autorizar violências, legitimar a desumanização de alguns/mas. Ter compromisso com esses processos diz de qual sociedade e espaços buscamos construir. 
Podemos perceber permanências e rupturas, assim como aproximações com outros contextos. Entretanto, defendemos como prática o constante questionamento, atenção ao particular e aquilo que aprendemos a ver como o mais "natural possível”. Quais processos pedagógicos vem sendo engendrados e administrados pela sociedade, cidades, escolas e quais saberes vem sendo (re)construídos? Quais investimentos podem ser realizados para que outras sociedades, cidades, escolas sejam (re)produzidas? Penso que não há uma resposta única e final. Somos sujeitos constantemente afetados/as pelo contexto em que estamos inseridos. No momento em que vivemos as novas tecnologias permitem que outras verdades, de outras localidades e realidades surjam nos espaços trazendo outras dinâmicas e possibilidades de (re)construção das relações de saber-poder.

\section{REFERÊNCIAS}

AZEVEDO, Aroldo de. As Cidades. In.: AZEVEDO, Aroldo de (org.). Brasil: a terra e o homem. São Paulo: Companhia Editora Nacional/EDUSP, 1970.

BADINTER, Elizabeth. $\boldsymbol{X Y}$ : sobre a identidade masculina. Rio de Janeiro: Nova Fronteira, 1993.

BAUMAN, Zygmunt. Globalização: as consequências humanas. Rio de Janeiro: Jorge Zahar Ed., 1999.

BRITZMAN, Deborah. O que é esta coisa chamada AMOR - identidade homossexual, educação e currículo. Revista Educação e Realidade, Porto Alegre, v. 21, p. 71-96, jan./jun. 1996.

BUTLER, Judith. Problemas de Gênero: Feminismo e subversão da identidade. Rio de janeiro: Editora Civilização Brasileira, 2003.

CONNELL, Raewyn. Políticas da masculinidade. Educação \& Realidade. Rio de Janeiro, 1995. Disponível em: <https://repositorio.ufsc.br/handle/123456789/1224> Acesso em: 17/06/2020.

FERRARI, Anderson Ferrari; BARBOSA, José Gabriel Couto de Viveiros.

Homossexualidades masculinas e cidade pequena. In: Revista Bagoas, Estudos Gays, Gênero e Sexualidade. UFRN n. 11, 2014, p. 211-236.

FERRARI, Anderson; DINALI, Wescley . Herança moderna disciplinar e controle dos corpos: quando a escola se parece com uma 'gaiola'. Educação em Revista (UFMG. Impresso), v. 28, p. 393-433, 2012. 
FERRARI, Anderson. Quem sou eu? Que lugar ocupo? Grupos gays, educação e a construção do sujeito homossexual. 2005. Tese (Doutorado). Universidade Estadual de Campinas, Campinas, 2005.

FERRARI, Anderson. "O QUE É LOBA??? É UM JOGO SINISTRO, SÓ PARA QUEM FOR HOMEM..." - GÊNERO E SEXUALIDADE NO CONTEXTO ESCOLAR. In: $30^{\circ}$ Reunião Anual da ANPED, 2007, Caxambu. Caderno de Resumos da $30^{\circ}$ Reunião Anual da ANPED. Caxambu: Armazém das Letras, 2007. p. 261.

FERRARI, Anderson. Ma vie en rose: gênero e sexualidades por enquadramento e resistências. Educação e foco, Juiz de Fora, v. 14, n. 1, p. 117-141, mar/ago 2009.

FOUCAULT, Michel. História da Sexualidade I: a vontade de saber. Tradução de Maria Thereza da Costa Albuquerque e J. A. Guilhon Albuquerque. Rio de Janeiro: Graal, 1988.

FOUCAULT, Michel. Vigiar e Punir: nascimento da prisão. Tradução de Raquel Ramalhete. Petrópolis/RJ: Vozes, 1999.

FOUCAULT, Michel. A arqueologia do saber. Tradução Luiz Felipe Baeta Neves. 7. ed. 3. reimp. Rio de Janeiro: Forense Universitária, 2008.

FRESCA, Tânia Mara. Em defesa dos estudos das cidades pequenas no ensino de geografia. Geografia, Londrina, v.10, n.01, p. 27-34, 2001.

GIDDENS, Anthony. Sociologia; tradução Sandra Regina Netz. 4. Ed. - Porto Alegre: Artmed, 2005.

LOURO, Guacira Lopes. Corpo, Escola e Identidade. Educação \& Realidade, Porto Alegre, v. 25, n. 2, p. 59-75, jul./dez. 2000a.

LOURO, Guacira Lopes. Pedagogias da sexualidade. In: LOURO, Guacira Lopes (Org.). O corpo educado: pedagogias da sexualidade. 2.ed. Tradução dos artigos: Tomaz Tadeu da Silva. Belo Horizonte: Autêntica, 2000b. P. 7-34.

LOURO, Guacira Lopes. Gênero, sexualidade e educação: Uma perspectiva pósestruturalista. Petrópolis, RJ: Vozes, 2003.

LOURO, Guacira Lopes. Heteronormatividade e homofobia. In: JUNQUEIRA, Rogério. Diniz (Org.). Diversidade sexual na educação: problematizações sobre homofobia nas escolas. Brasília: Ministério da Educação/UNESCO, 2009. v. 32. p. 85-93.

MARSHALL, James. Michel Foucault: pesquisa educacional como problematização. In: PETERS, Michael e BESLEY, Tina. Por que Foucault? Novas diretrizes para a pesquisa educacional. Porto Alegre: Artmed, 2008.

MISKOLCI, Richard. Teoria Queer: um aprendizado pelas diferenças. Belo Horizonte: Autêntica Editora/UFPO, 2012. 80 p. (Série Cadernos da Diversidade, 6).

PETERS, Michael. Pós-estruturalismo e filosofia da diferença (uma introdução). Belo Horizonte: Autêntica, 2000. 
RICHARDSON, Niall. Effeminophobia, Misogyny and Queer Friendship: The Cultural Themes of Channel 4's Playing it Straight. Sexualities, v. 12, n. 4, p. 525-544, 2009.

SANTOS, Luiz Henrique Sacchi dos. Sobre o etnógrafo-turista e seus modos de ver. In: COSTA, Marisa Vorraber; BUJES, Maria Isabel Edelweiss. Caminhos investigativos III: riscos e possibilidades de pesquisar nas fronteiras. Rio de Janeiro: DP\&A, 2005, p. 9-22.

SCOTT, Joan Wallach. Gênero: uma categoria útil para análise histórica. Educação \& Realidade, Porto Alegre, v.20, n.2. jul.-dez., p.71-99, 1995.

SILVA, Moacir Malheiros Fernandes. Tentativa de classificação das cidades brasileiras. Revista Brasileira de Geografia, Recife, v. 8, n. 3, p. 3-36, 1946.

VEIGA-NETO, Alfredo. Pensar a escola como uma instituição que pelo menos garanta a manutenção das conquistas fundamentais da Modernidade. In: COSTA, Marisa Vorraber (Org.). A escola tem futuro? Rio de Janeiro: Lamparina, 2003. p. 97 - 118.

VEIGA-NETO, Alfredo. Olhares... In: COSTA, Marisa Vorraber Costa (org.) Caminhos investigativos I: novos olhares na pesquisa em educação. Rio de Janeiro: Lamparina, 2007, p. $39-60$.

VEIGA-NETO, Alfredo. Crise da modernidade e inovações curriculares: da disciplina para o controle. Revista de Ciências da Educação, Lisboa, n. 7, p. 141-149, set./dez. 2008.

WOODWARD, Katryn. Identidade e diferença: uma introdução teórica e conceitual. In: SILVA, Tomaz Tadeu da. Identidade e diferença: A perspectiva dos Estudos Culturais. SILVA, Tomaz Tadeu da (org.). 9. ed. - Petrópolis, RJ: Vozes, 2009.

Submetido em: 22/09/2020

Aprovado em: 07/10/2020 